\title{
Investigation of Different Modulation Formats for Extended Reach NG-PON2 using RSOA
}

\author{
S. Rajalakshmi ${ }^{1}$ \\ ECE, SENSE, VIT, Vellore, \\ Tamil Nadu, India
}

\author{
T. Shankar ${ }^{2}$ \\ ECE, SENSE, VIT, Vellore, \\ Tamil Nadu, India
}

\begin{abstract}
Global market forecasts predicted that by $\mathbf{2 0 2 0}$, more than 26 billion internet devices and connections universally interconnected will require nearly 3 times the data traffic generated when compared to the year 2015. The increase in data traffic, demands for enormous bandwidth capacity. The potential to deliver 10 Gbps of huge data to individual businesses and households will be of paramount importance and a challenging issue for the present day service providers. An intensive study is carried out for the Fiber-To-The-Home Passive Optical Network (FTTH PON) for their use in the optical communication, due to their high data rates and more bandwidth. The current evolution of Next Generation-Passive Optical Networks Stage 2 (NGPON2) network is the primary key technology for the growing demands of higher bandwidth and transmission of the data to the subscribers present in the access network from the service providers. Time Wavelength Division Multiplexing PON (TWDM-PON) architecture is the viable essential solution for NG-PON2 which provides more bandwidth for bidirectional transmission. This article proposes a design for extended reach TWDM-PON based on reflective semiconductor optical amplifier (RSOA). The exclusive feature of the RSOA is the wavelength conversion, which replaces the transmitters in the subscriber end. The Quality of Service (QoS) performance is critically analyzed for different optical modulation formats in proposed extended reach TWDM-PON using RSOA. The TWDM-PON using RSOA is simulated and investigated for different photodetectors. The analysis is also carried for various distance and data rates. The results exhibited that APD receivers have better performance of minimum bit error rate obtained is $\mathbf{1 0}^{-11}$ and minimum $Q$ factor is 6.2 when compared with PiN receivers. The comparative analysis of different modulation formats shows that the Carrier Suppressed Return to Zero- Differential Phase Shift Keying (CSRZ-DPSK) gives the best performance for longer distance and large data rates and Return to Zero(RZ) gives the least performance.
\end{abstract}

Keywords-Fiber To The Home (FTTH); Passive Optical Network (PON); Next Generation-Passive Optical Networks Stage 2 (NG-PON2); Quality of Service (QoS); Reflective Semiconductor Optical Amplifier (RSOA); Time and Wavelength Division Multiplexing (TWDM)

\section{INTRODUCTION}

In today's world we are bombarded with high performance networking system like laptops, smartphone, and their applications requiring more bandwidth like Internet of Things (IoT), remote medical services, cloud computing, file sharing, cloud storage, video and web conference, online audio and video streaming. The rapid increase in bandwidth demand for commercial applications drives the intensive tremendous need of high data rates at the subscriber end. Subscribers with high bandwidth are facilitated with faster data transfer speed, reduced crashes, bounces or busy signals, faster application performance, allows for more simultaneous users, increased data transfer capability and enabling more interactivity etc. NG-PON2 technology is outstripping the user demand. Flexible services towards the consumer are also provided by NG-PON2. Low latency and Quality of Experience (QoE) will be guaranteed to the customers by NG-PON2. The modern technique to get high data rates at end users is by implementing NG-PON2 network.

The TWDM-PON has been a key technique for NGPON2. It is the first point to multi point wavelength access that provides data rate of $40 \mathrm{Gbps}$, for a distance of $40 \mathrm{Km}$ without amplifier which is cost effective solution and has very high efficiency. Service operators require NG-PON2 systems for having higher capacity, huge bandwidth, more users and for longer reach. The article describes about the TWDM-PON for upstream using burst mode and downstream using continuous mode for $50 \mathrm{~Gb} / \mathrm{s}$ transmission using Non-returnto-Zero(NRZ) modulation formats and optical amplifiers [1].

In this article, a bidirectional TWDM-PON is proposed using NRZ modulation format for high capacity of $80 \mathrm{Gbps}$ for a distance of $50 \mathrm{Km}$ with minimum BER by using power optimization process of 5 to $10 \mathrm{dBm}$ [2]. This paper explains the analysis of the performance of TWDM-PON for different reach and wavelength variation in ONU by using NRZ and Pulse-amplitude modulation (PAM4) in intensity modulation and direct detection [3]. In this paper they analyzed Manchester, Differential Phase Shift Keying (DPSK) and Differential Quadrature Phase Shift Keying (DQPSK) for different distances and different data rates. They described in terms of Bit Error Rate (BER) and Quality factor (Q- factor) for optical systems [4].

In this paper they have investigated the necessary prerequest required for NRZ Feed forward Equalization(FFE) and Decision Feedback Equalizer(DFE) and Duo-binary based adaptive equalization techniques for the design of 25 GigabitEthernet Passive Optical Network(G-EPON). They demonstrated and compared for different number of taps and modulation formats, where duo binary shows better results than NRZ [5]. The NG-PON2 based on Nyquist NRZ technique for downstream transmission based on Direct Modulated Laser (DML) and APD. It shows superiority as $28.4 \mathrm{dBm}$ in receiver sensitivity for TWDM-PON network [6]. The article analyzed and compared the advance modulation 
formats such NRZ, RZ, Duobinary and PAM-4 for 8 channel WDM-PON for different data rates without amplifiers and dispersion compensation [7].

The article investigates the performance of residual dispersion, dispersion tolerance and spectral efficiency, for correlative coding using NRZ and RZ for intensity modulation using direct detection an coherent receiver for $40 \mathrm{Gbps}$ data transmission for $30 \mathrm{~km}$ Standard Mode Fibre (SMF) [8]. Using SMF and Dispersion Compensation Fiber (DCF) design composition of pre, post and symmetrical fiber composition, they achieved high data rate and long transmission over existing fibre optic systems [9]. Demonstration of 100G-PON based on NRZ transmission using Germanium and Silicon Avalanche Photo detector (APD) proved sufficient power budget for high data rate transmission [10].

In this paper they simulated asymmetrical Next Generation-passive Optical Network (XG-PON) for a upstream and downstream transmission using RZ and CSRZ. They analyzed these modulation schemes for different fiber length. The performance is affected by Polarization Mode Dispersion (PMD) and CSRZ provides best performance when compared to RZ format [11]. A new NG-PON2 is designed for 2048 users using TWDM-PON architecture for long reach of $100 \mathrm{Km}$ using optical amplifiers. The amplifier emission noise power and saturation power of optical amplifier and splitter losses are simulated and evaluated. The design is analyzed for QoS parameter [12].

The article gives the summary of different modulation schemes such as RZ, RZ-DPSK, NRZ, NRZ-DPSK, CSRZDPSK and DB in the design of WDM-PON data transmission[13]. The author investigated DPSK signal for downstream in the proposed WDM-PON with RSOA in ONU for a distance of $25 \mathrm{Km}$. The upstream signal remodulated noise is reduced by using Orthogonal Frequency Division Multiplexing(OFDM). The results exhibited better BER of 10 ${ }^{10}[14]$. The paper investigates currently used modulation formats such as NRZ, RZ, CSRZ and DB in terms of BER, Q factor, optical reach and distance, they analyzed under polarization effects, dispersion and spectral efficiency [15].

This paper reviews the different types of advanced modulation formats supported proposed architectures used to carry high capacity of 400 Gigabit Ethernet links. Their optical link power budget, digital complexity, and power dissipation are compared via simulations. The challenges of implementing the physical layer are discussed [16]. Advanced modulations formats and detection techniques based on low power and integrated optical modulators are used in this design to reduce the cost and energy. The impairments induced by all kinds of defects and bandwidth limitation of opto-electronic components and the corresponding compensation techniques based on DSP algorithms have also been discussed in the experiments [17].

Design of downlink/uplink unicast 8 channel of each 2.5 $\mathrm{Gb} / \mathrm{s}$ and one $10 \mathrm{~Gb} / \mathrm{s}$ broadcast channel with the use of the cyclic property of arrayed waveguide grating with reflective capabilities of the fiber Bragg grating which produces colourless operation in TWDM-PON. The maximum allowable power budget loss for the network is about $36.5 \mathrm{~dB}$ with the receiver sensitivity for all ONUs obtained is 29.83 $\mathrm{dBm}$ [18]. RSOA is used to design a TWDM-PON for do transmission and DML for upstream transmission with filters for analyzing the power budget for different modulation formats [19].

This article proposes a WDM-OFDM-RoF system based on optical coupling tandem single-sideband (O-TSSB) transmitter. The impact of harmonic distortion and intermodulation distortion in this system is theoretically investigated and demonstrated to reduces the nonlinear distortion effectively by the use of (O-TSSB) transmitter with modulation index of 0.6 for distance of $50 \mathrm{Km}$ with a BER of $10^{-3}[20]$. The author presents a comparative analysis of power sensitivity of the receiver under different modulation formats in SMF. Four modulation techniques were used namely "Return to Zero" (RZ), "Non Return to Zero" (NRZ), Duobinary (DB) and Differential Quadrature Phase Shift Keying (DQPSK). The result indicated DQPSK to be the smartest among all followed by DB. NZR showed moderate performance in general. RZ showed the worst performance in WDM system [21].

We propose four strategies for TDHMF Tx operation. BER minimization permits PM-QPSK/PM-16QAM performance similar to PM-8QAM's. In TDHMF nonlinear propagation, predistortion and/or polarization interleaving enables the maximum reach predicted by GN-model [22]. The $40 \mathrm{Gbps}$ is PON is designed using different modulation formats such as NRZ-OOK, RZ-OOK, RZ-DPSK, and RZDQPSK for $20 \mathrm{~km}$ distance using TDMA and OCDMA with zero dispersion at BER less than $10^{-3}$ [23]. The paper discusses the WDM-PON for long reach and short reach applications. They calculated the loss budget for different modulation [24]. The manuscript analysis about the performance of the design of WDM-PON by using advanced modulation formats which requires intensity modulation and phase modulation for the service factor of power, noise, crosstalk, dispersion and polarization [25].

The article is organized as follows: the introduction section consists of the background literature survey. The second section describes the proposed design methodology with the suitable codes and standards adopted in NG-PON2. Then next section explains the summary and discussion of the results obtained for different modulation formats used in NG-PON2 network.

\section{Proposed Design OF NG-PON2}

The proposed design of NG-PON2 is based on Hybrid TWDM-PON architecture for extended reach, which consists of 3 sections, a Central office (CO), Optical Distribution Network (ODN) and Optical Network Unit (ONU). The hybrid TDM-WDM PON is shortly called as TWDM-PON. The principle of operation of NG-PON2 is based on TWDMPON architecture. NG-PON2 is designed to operate in bidirectional direction. When the data is carried from OLT to ONU it is called Down Stream (DS) transmission and when the data is carried from ONU to OLT it is called Up Stream (UP) transmission. During DS it follows Wavelength Division Multiplexing (WDM) principle and during US it follows Time Division Multiplexing (TDM) principle. 
The NG-PON2 consist of 8 number of OLT which includes eight DS transmitter unit and eight US receiver unit. The ODN consists of multiplexer/demultiplexer, circulator, bidirectional fiber and 1:8 power splitter and eight ONU DS receiver and eight ONU US transmitters are present in this design. Here NG-PON2 is arranged according to the wavelength stacking technology for an extended reach of 100 $\mathrm{Km}$ using RSOA. The proposed design of TWDM-PON network is considered for direct detection system and for nonpolarization multiplexing signals. Direct detection is typically used for $40 \mathrm{~Gb} / \mathrm{s}$ or lower-speed systems. In a direct detection receiver, its photo-detector only responds to changes in the receiving signal optical power, and cannot extract any phase or frequency information from the optical carrier. The proposed TWDM-PON architecture for extended reach NGPON2 is shown in Fig. 1.

Basic formats like Non- Return to Zero (NRZ), Return to Zero(RZ) and DB and advanced formats such as Non- Return to Zero-Differential Phase Shift Keying (NRZ-DPSK), Return to Zero- Differential Phase Shift Keying (RZ-DPSK), and Carrier Supressed Return to Zero- Differential Phase Shift Keying (CSRZ-DPSK) are considered in this article. The basic modulation formats supports $200 \mathrm{GHz}$ to $100 \mathrm{GHz}$ channel spacing with spectral efficiency of $0.5 \mathrm{bits} / \mathrm{sec} / \mathrm{Hz}$ and supports shorter distance of 200 miles. The advanced modulation formats supports $100 \mathrm{GHz}$ to $50 \mathrm{GHz}$ with spectral efficiency of $1 \mathrm{bits} / \mathrm{sec} / \mathrm{Hz}$.

The downstream operation consist of eight OLT transmitters with eight wavelength channels specified from 187.1-187.8 THz with fixed channel spacing of $100 \mathrm{GHz}$ grid.

The eight wavelengths are modulated with different modulation formats starting with basic NRZ modulation as shown in Fig. 1. The modulated downstream signals are then multiplexed using an optical multiplexer and transmitted through a single mode optical fibre running for $90 \mathrm{Km}$ is fed to the eight ONU by using passive power splitter with 1:8 ratio.

The downstream data transmission acts as a broadcast transmission, which splits the equal optical power to different wavelength ONU DS receivers. Semiconductor photodiodes are the most commonly used detectors in optical fiber systems since they provide good performance, being small in size, and are of low cost. The DS optical signal from power splitter is detected by PIN photodetector. The power splitter and the DS ONU are connected by a distribution fiber running for $10 \mathrm{Km}$. therefore the total distance achieved is $100 \mathrm{Km}$. The same DS signal is given to RSOA via Fabry perot free spectral range (FPF) to separate the DS signal from US signal.

The DS signal wavelength is reused by RSOA for US wavelength transmission. It considerably reduces the ONU transmitters and the cost also. Therefore no synchronization problem exists. The upstream signal is once again remodulated by RSOA. The same process will be continued for other remaining seven wavelength and feed to the optical fiber cable (OFC) via 1:8 splitter following TDM. The US signal then travels the OFC and reaches the US receiver. The US and DS signals are separated by using the circulator present at both OLT and ONU ends. The US signals are detected by PiN photodetector and perform O-E conversion. Subsequently, the converted electrical signals are sent to Bessel LPF for filtration process and followed by $3 \mathrm{R}$ generator for reshaping, restoring and retiming of the original electrical signal. The original electrical signal is fed to BER analyser to measure the BER value. BER is measured at both ONU receiver for DS and OLT for US receiver.

In the basic Fig. 1 the downstream OLT transmitter is designed separately according to the different modulation types considered in this article. Fig. 2 shows the DS OLT NRZ transmitter, Fig 3 shows the DS OLT RZ transmitter, Fig. 4 shows the DS OLT NRZ-DPSK transmitter, Fig. 5 shows the DS OLT RZ-DPSK transmitter, Fig. 6 shows the DS OLT CSRZ-DPSK transmitter, Fig. 7 shows the DS OLT DB transmitter. These different modulation transmitters are incorporated in the basic design of wavelength stacking NGPON2 (Fig. 1) and simulated separately.

The OLT unit consists of Phase Pattern Generator (PPG) period of $27^{-1}$ to examine the high speed connections. A randomly generated sequence is then coded with NRZ pulses for reference encoder. $\mathrm{CW}$ laser source generates a continuous optical beam of having a power of $3 \mathrm{dBm}$. CW laser and NRZ pulses is further fed for the process of modulation into the MZM. The optical wave amplitude is controlled by MZM having ratio of extinction at $30 \mathrm{~dB}$. The signal is then modulated optically. The simulation operation process is repeated for different modulation formats given in figure from Fig. 2 to Fig. 7. The simulation input specifications are given in the Table I.

TABLE. I. Simulation Key PARAMETERS USED

\begin{tabular}{|l|l|}
\hline Parameters & Values \\
\hline Data Rate & $10 \mathrm{Gbps}$ \\
\hline Transmitter Power & $0 \mathrm{dBm}$ \\
\hline Fibre Back Haul length & $90 \mathrm{Km}$ \\
\hline Fiber distribution section & $10 \mathrm{Km}$ \\
\hline Fiber dispersion coefficient & $16.75 \mathrm{ps} / \mathrm{nm} / \mathrm{km}$ \\
\hline Extinction ratio & $30 \mathrm{~dB}$ \\
\hline Attenuation coefficient & $0.30 \mathrm{~dB} / \mathrm{km}$ \\
\hline Channel spacing & $100 \mathrm{GHz}$ \\
\hline Power splitter insertion loss & $1.5 \mathrm{~dB}$ \\
\hline PIN Receiver responsivity & $0.6 \mathrm{~A} / \mathrm{W}$ \\
\hline APD Responsivity & $0.9 \mathrm{~A} / \mathrm{W}$ \\
\hline Receiver Sensitivity & $-20 \mathrm{dBm}$ \\
\hline Receiver Electrical Bandwidth & $7.5 \mathrm{GHz}$ \\
\hline RSOA Bias Current & $50 \mathrm{~mA}$ \\
\hline RSOA Output Power & $1.85 \mathrm{dBm}$ \\
\hline RSOA average Gain & $15.78 \mathrm{~dB}$ \\
\hline
\end{tabular}




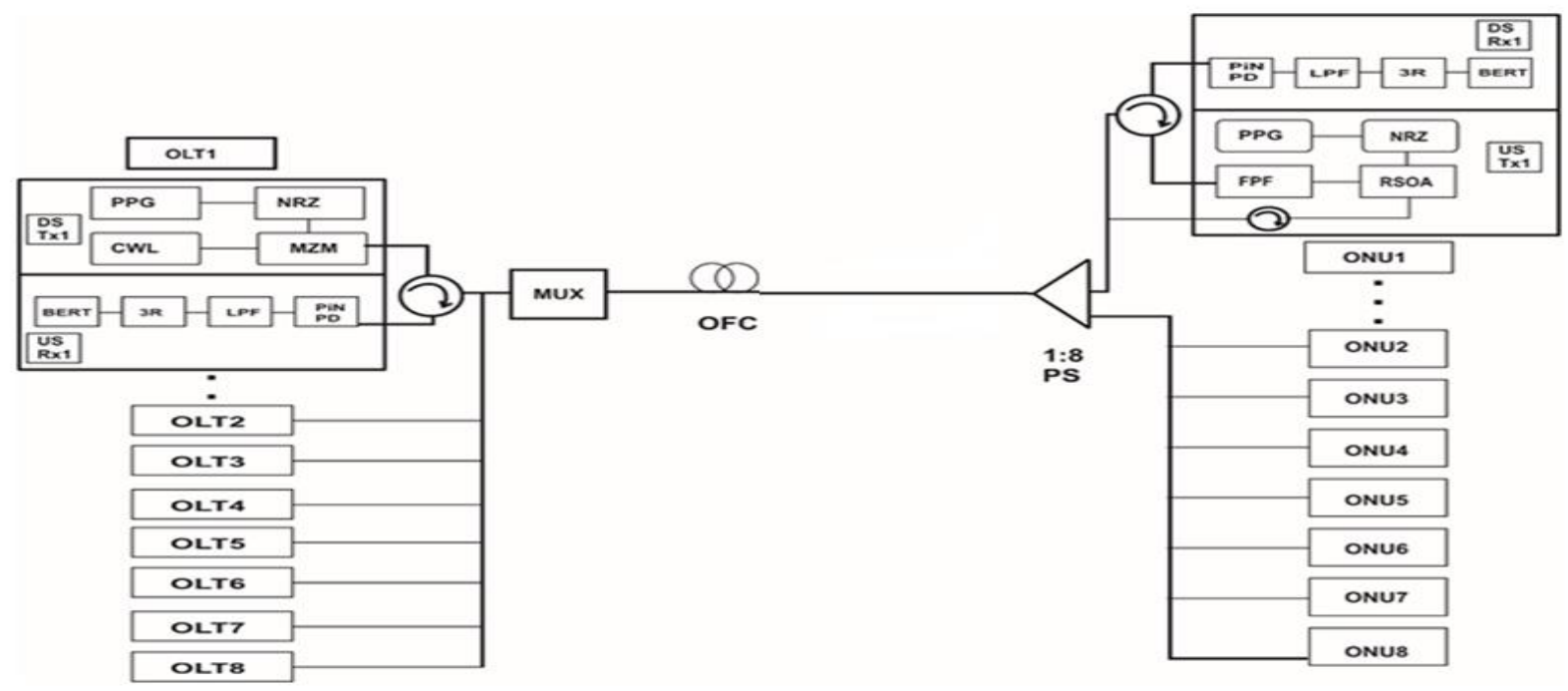

Fig. 1. The Schematic Stacked Wavelength Model for NG-PON2.

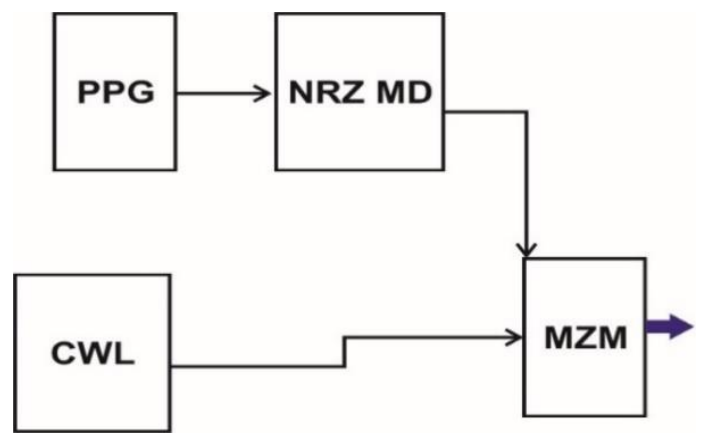

Fig. 2. DS OLT NRZ Transmitter.

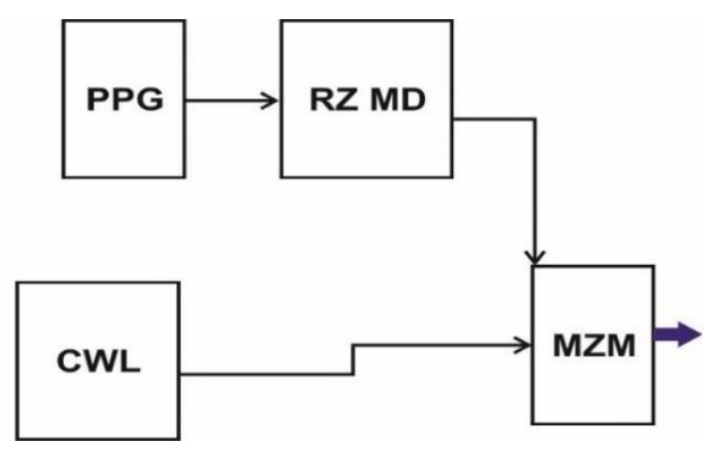

Fig. 3. DS OLT RZ Transmitter.

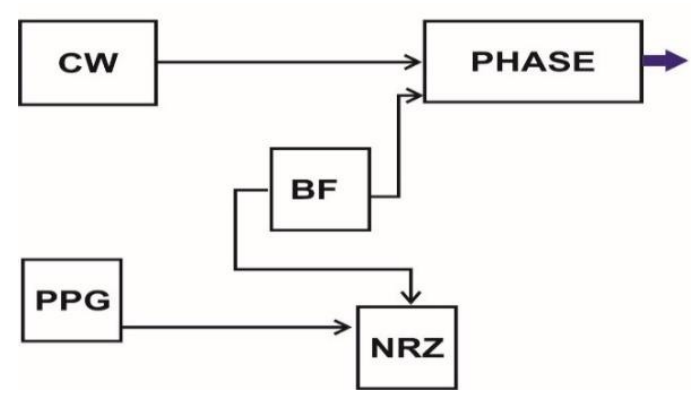

Fig. 4. DS OLT RZ-DPSK Transmitter.

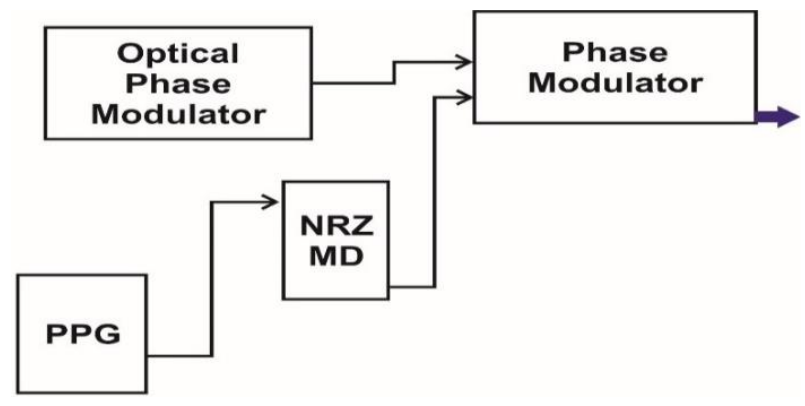

Fig. 5. DS OLT RZ-DPSK Transmitter.

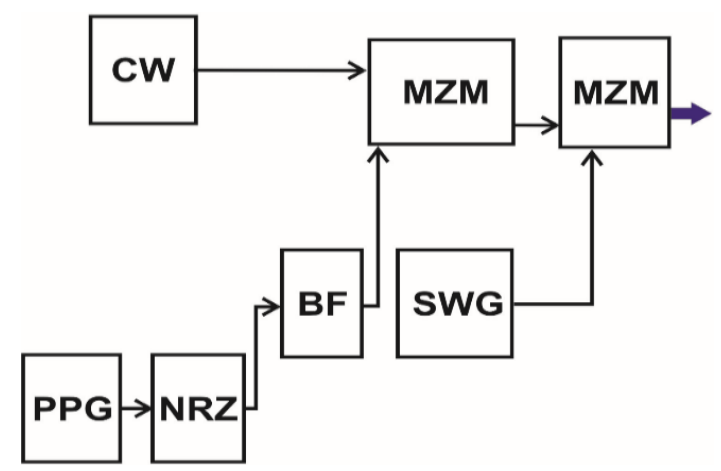

Fig. 6. DS OLT CSRZ-DPSK Transmitter.

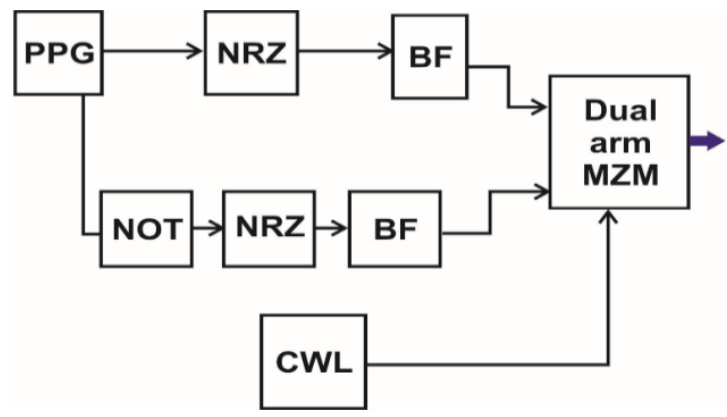

Fig. 7. DS OLT Duobinary Transmitter. 


\section{RESULTS AND DISCUSSION}

The proposed wavelength stacking NG-PON2 network is designed and implemented in Optisystem 13.0 simulation tool using Optiwave photonic software. The simulation is carried out and investigated for different distance from $10 \mathrm{Km}$ to 100 $\mathrm{Km}$ for different modulation formats. The simulation is also carried out and investigated for different data rate from 10 $\mathrm{Gb} / \mathrm{s}$ to $80 \mathrm{Gbps}$ for different modulation formats The analysis is also investigated for different types of receiver configuration like PIN photodetector and APD photo detector for the above conditions of distance and data rate for different modulation. In this article QoS analysis have been carried out mainly for 2 important factors like Bit Error Rate (BER) and Q-Factor for different modulation formats such as NRZ, RZ, NRZ-DPSK, RZ-DPSK, CSRZ-DPSK and Duobinary. The analysis is also done for downstream transmission and upstream transmission.

\section{A. PIN Receivers Performance}

1) BER analysis for various distance: The effect of distance factor is analyzed using PIN receiver. It is shown in the Fig. 8. The effect of distance is analyzed in terms of BER and it is compared with all the six types of modulation formats. CSRZ-DPSK modulation format gives the best performance of BER value of $5 * 10^{-9}$, the next good performance is given by NZR-DPSK of BER value of $2.5^{*} 10^{-9}$ , followed by RZ-DPSK and the least performance of $5^{*} 10^{-7}$ for $\mathrm{RZ}$ format at $10 \mathrm{Km}$. At $100 \mathrm{Km}$ distance the BER value increases from $4 * 10^{-8}$ to $10^{-7}$. For the long distance data communication, choosing the optimum BER in CSRZ-DPSK, NRZ-DPSK, RZ-DPSK can be used for optimum distance. Similar performance characteristics is obtained for upstream transmission also.

2) $Q$ factor analysis for various distance: The effect of distance factor is analyzed using PIN receiver. It is shown in the Fig. 9. The effect of distance is analyzed in terms of $\mathrm{Q}$ factor and it is compared with all the six types of modulation formats. CSRZ-DPSK modulation format gives the best performance of $\mathrm{Q}$ factor value of 6.19 , the next good performance is given by NZR-DPSK of q factor value of 5.96 followed by RZ-DPSK and the least performance is given by $\mathrm{RZ}$ format of value 5.25 and is observed at $10 \mathrm{Km}$.

For maximum distance of $100 \mathrm{Km}$, the $\mathrm{Q}$ factor decreases from 5.97 to 5.12. For the long distance data communication, choosing the optimum Q factor in CSRZ-DPSK, NRZ-DPSK, RZ-DPSK can be used for optimum distance. As the distance increases, the $\mathrm{Q}$ factor decreases. Similar performance characteristics are obtained for upstream transmission.

\section{B. APD Receivers Performance}

1) BER analysis for various distance: The effect of distance factor is analyzed using PIN receiver. It is shown in the Fig. 10. The effect of distance is analyzed in terms of BER and it is compared with all the six types of modulation formats. CSRZ-DPSK modulation format gives the best performance of BER value of $5.7 * 10^{-11}$, the next good performance is given by NZR-DPSK of BER value of $4 * 10^{-11}$ followed by RZ-DPSK and the least performance is RZ format is $5^{*} 10^{-8}$ at the distance of $10 \mathrm{Km}$. . At $100 \mathrm{Km}$ the BER value increases from $5 * 10^{-9}$ to $3 * 10^{-8}$. For the long distance data communication choosing the optimum BER in CSRZ-DPSK, NRZ-DPSK, RZ-DPSK can be used for optimum distance Similar performance characteristics is obtained for upstream transmission.

The effect of distance factor is analyzed using PIN receiver. It is shown in the Fig. 11. The effect of distance is analyzed in terms of Q factor and it is compared with all the six types of modulation formats. CSRZ-DPSK modulation format gives the best performance of $Q$ factor value of 6.1, the next good performance is given by NZR-DPSK of $\mathrm{q}$ factor value of 6.0 followed by RZ-DPSK and the least performance is given by RZ format of value 5.42 observed at $10 \mathrm{Km}$. For maximum distance of $100 \mathrm{Km}$, the $\mathrm{Q}$ factor decreases from 5.96 to 5.25. For the long distance data communication choosing the optimum Q factor in CSRZ-DPSK, NRZ-DPSK, RZ-DPSK can be used for optimum distance. As the distance increases, the $\mathrm{Q}$ factor decreases. Similar performance characteristics are obtained for upstream transmission.

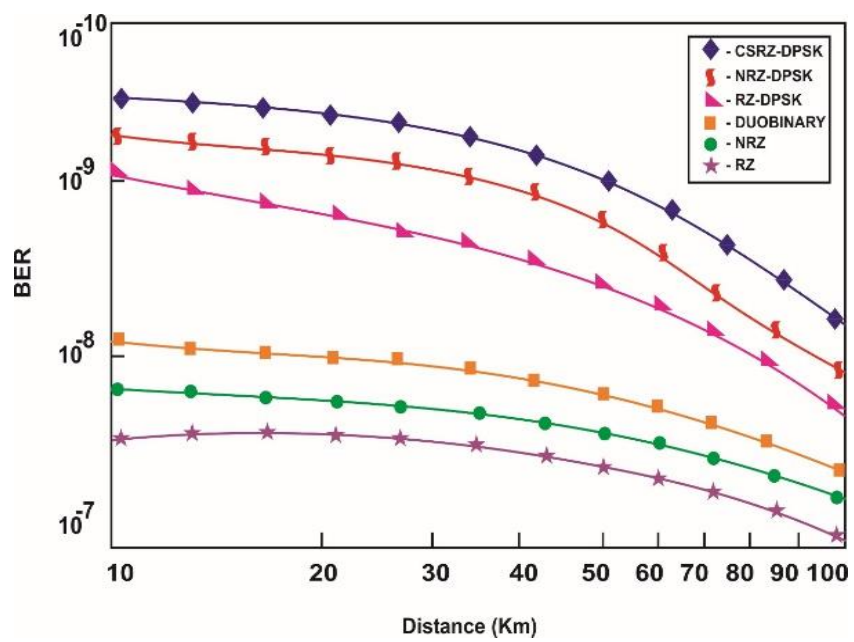

Fig. 8. Performance of BER for Distance Factor using PIN Receivers.

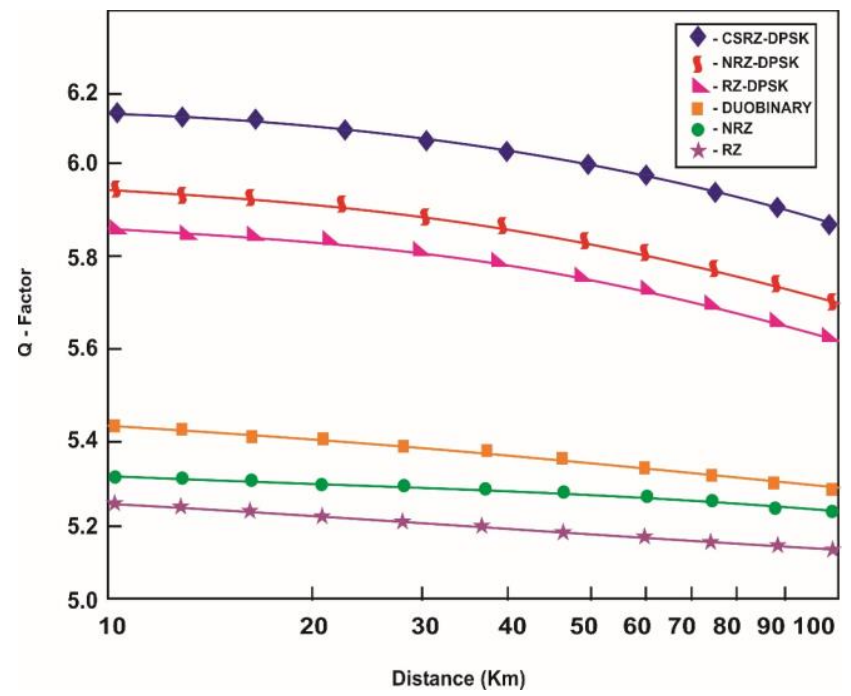

Fig. 9. Performance of Q Factor for Distance Factor using PIN Receivers. 


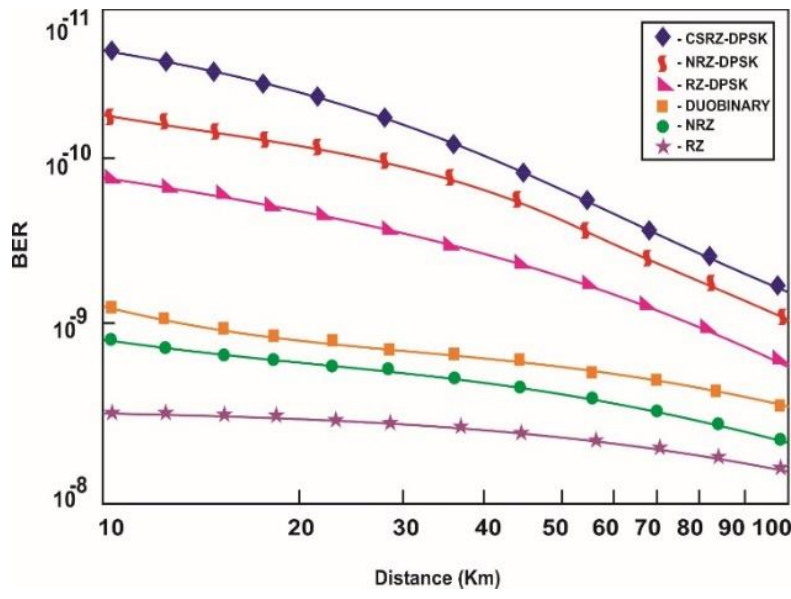

Fig. 10. Performance of BER Factor for Distance Factor using APD Receivers.

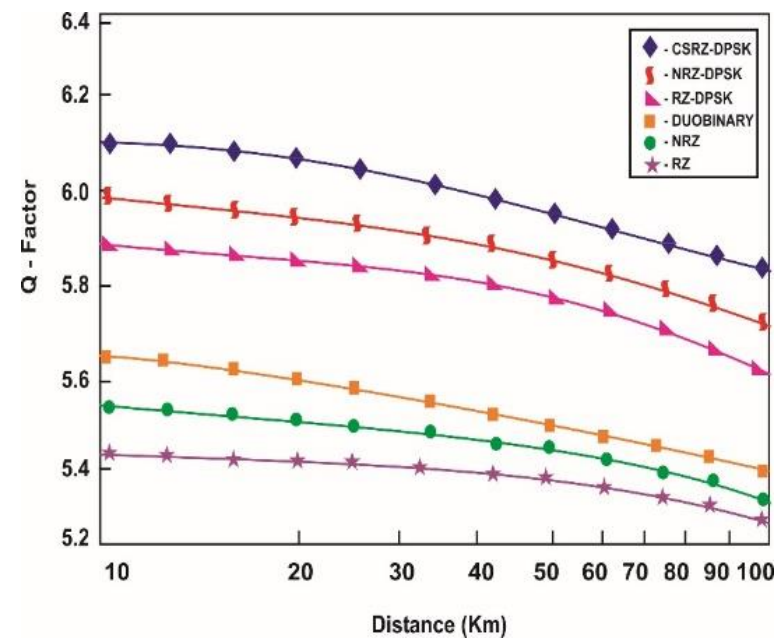

Fig. 11. Performance of Q Factor for Distance Factor using APD Receivers.

\section{PIN Receivers Performance}

1) BER analysis for various Data rate: The effect of data rate is analyzed using PIN receiver. It is shown in the Fig. 12. The effect of data rate is analyzed in terms of BER and it is compared with all the six types of modulation formats. CSRZDPSK modulation format gives the best performance of BER value of $7 * 10^{-10}$, the next good performance is given by NZRDPSK of BER value of $5^{*} 10^{-10}$, followed by RZ-DPSK and the least performance of $5^{*} 10^{-7}$ for RZ format at $10 \mathrm{~Gb} / \mathrm{s}$ data rate. At $80 \mathrm{~Gb} / \mathrm{s}$ distance the BER value increases from $8 * 10^{-9}$ to $2 * 10^{-7}$. For increased data rate choosing the optimum BER in CSRZ-DPSK, NRZ-DPSK, RZ-DPSK can be used. Similar performance characteristics is obtained for upstream transmission

2) $Q$ factor analysis for various Data rate: The effect of distance factor is analyzed using PIN receiver. It is shown in the Fig. 13. The effect of data rate is analyzed in terms of Q factor and it is compared with all the six types of modulation formats. CSRZ-DPSK modulation format gives the best performance of $\mathrm{Q}$ factor value of 6.1, the next good performance is given by NZR-DPSK of q factor value of 5.9 followed by RZ-DPSK and the least performance is given by RZ format of value 5.22 observed at $10 \mathrm{Gbps}$. For maximum data rate of $100 \mathrm{Gbps}$, the $\mathrm{Q}$ factor decreases from 5.97 to 5.2. For the long distance data communication choosing the optimum Q factor in CSRZ-DPSK, NRZ-DPSK, RZ-DPSK can be used for optimum distance. As the distance increases, the $\mathrm{Q}$ factor decreases. Similar performance characteristics is obtained for upstream transmission.

\section{APD Receivers Performance}

1) BER analysis for various Data rate: The effect of data rate is analyzed using PIN receiver. It is shown in the Fig.14.The effect of data rate is analyzed in terms of BER and it is compared with all the six types of modulation formats. CSRZ-DPSK modulation format gives the best performance of BER value of $8^{*} 10^{-11}$, the next good performance is given by NZR-DPSK of BER value of $5^{*} 10^{-11}$, followed by RZDPSK and the least performance of $5 * 10^{-8}$ for RZ format at 10 $\mathrm{Gb} / \mathrm{s}$ data rate. At $80 \mathrm{~Gb} / \mathrm{s}$ distance the BER value increases from $7 * 10^{-10}$ to $2 * 10^{-8}$. For increased data rate choosing the optimum BER in CSRZ-DPSK, NRZ-DPSK, RZ-DPSK can be used. Similar performance characteristics is obtained for upstream transmission.

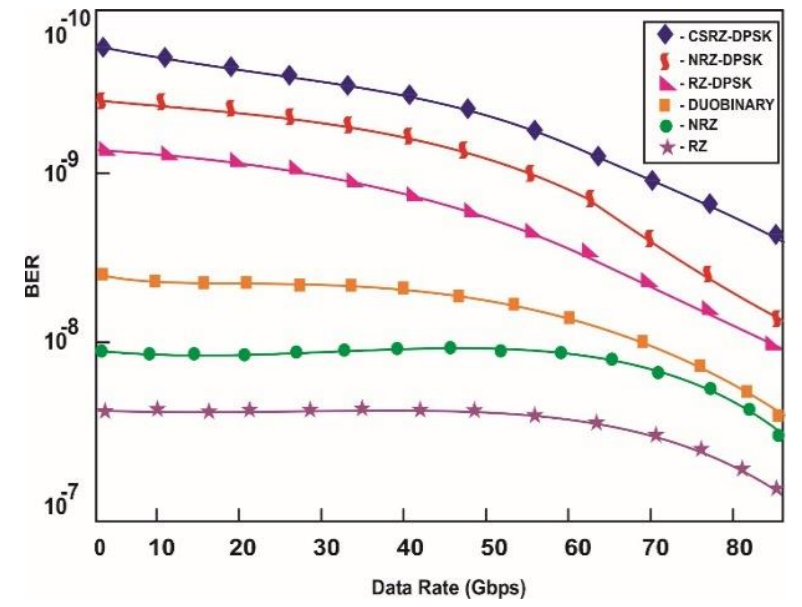

Fig. 12. Performance of BER for Various Data Rate using PIN Receivers.

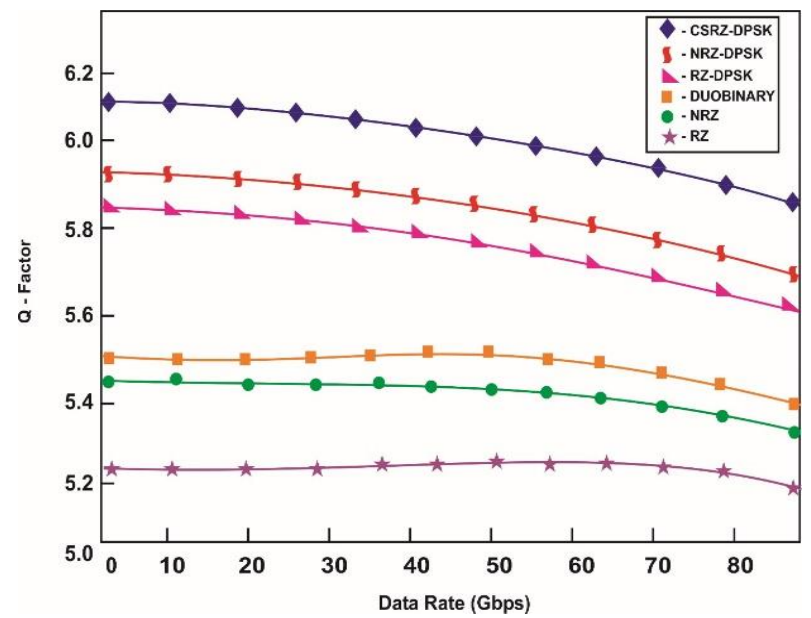

Fig. 13. Performance of Q Factor for Various Data Rate using PIN Receivers. 


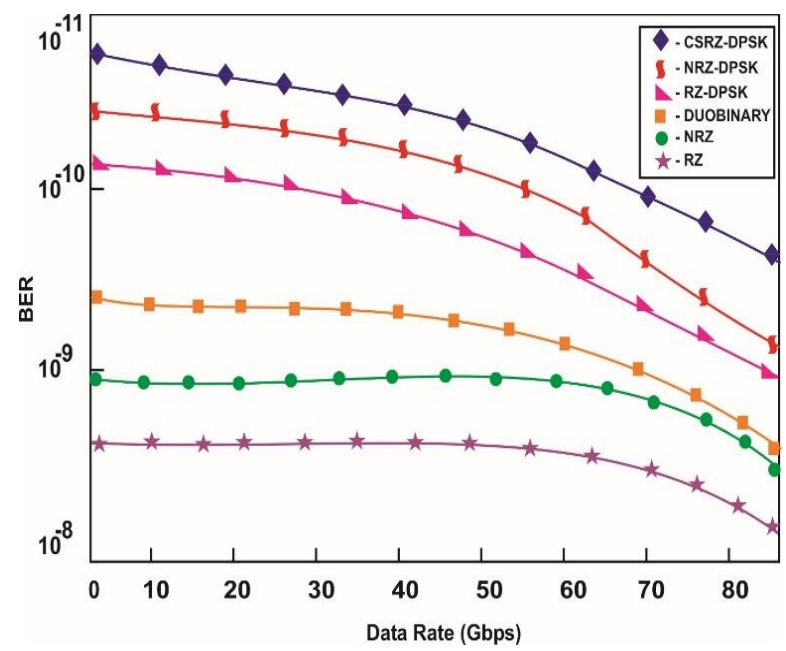

Fig. 14. Performance of BER for Data Rate Factor using APD Receivers.

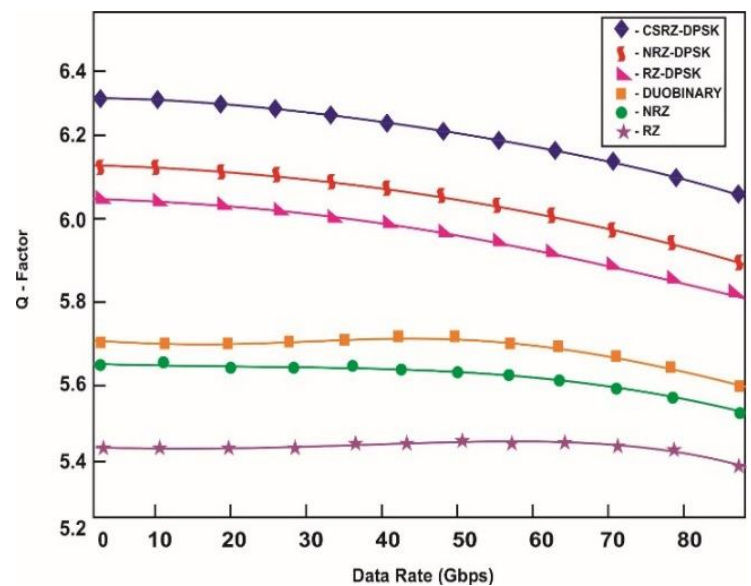

Fig. 15. Performance of Q Factor for Data Rate Factor using APD Receivers.

The effect of distance factor is analyzed using PIN receiver. It is shown in the Fig. 15. The effect of data rate is analyzed in terms of Q factor and it is compared with all the six types of modulation formats. CSRZ-DPSK modulation format gives the best performance of $\mathrm{Q}$ factor value of 6.1, the next good performance is given by NZR-DPSK of q factor value of 5.9 followed by RZ-DPSK and the least performance is given by RZ format of value 5.22 observed at $10 \mathrm{Gbps}$. For maximum data rate of $100 \mathrm{Gbps}$, the $\mathrm{Q}$ factor decreases from 5.97 to 5.2. For the long distance data communication choosing the optimum Q factor in CSRZ-DPSK, NRZ-DPSK, RZ-DPSK can be used for optimum distance. As the distance increases, the $\mathrm{Q}$ factor decreases. Similar performance characteristics are obtained for upstream transmission.

\section{CONCLUSION}

In this article wavelength stacking architecture of NGPON2 for extended reach is designed, implemented and simulated for various modulation formats using RSOA. The design is analyzed for various factor of increasing distance and increasing data rate. The factors are also investigated for different receiver operation and also for both downstream and upstream transmission. Similar characteristics are observed for upstream and downstream. CSRZ-DPSK gives minimum BER performance of $5 * 10^{-9}$ and minimum Q factor of 5.22 at the maximum distance of $100 \mathrm{Km}$ than all other codes in downstream transmission. The APD receivers' receiver performs better when compared to PIN receivers for both distance and data rate factor. RZ gives the least performance.

\section{ACKNOWLEDGMENT}

This research was done in VIT, Vellore, but not funded by VIT Vellore. The author would like to acknowledge the management VIT for supporting this work to be carried out in the successful manner.

\section{REFERENCES}

[1] Borkowski, R., Schmuck, H., Cerulo, G., Debrégeas, H., \& Bonk, R., "Single-Wavelength Symmetric $50 \mathrm{Gbit} / \mathrm{s}$ Equalization-Free NRZ IM/DD PON with up to $33 \mathrm{~dB}$ Loss Budget and Fiber Transmission over> 40 km", Optical Fiber Communication Conference, pp. W2A-26, 2019.

[2] Aly, M. H., \& Saleh, M. B, "Evaluation and optimization of TWDMPON system capacity over single bidirectional optical fiber: Migration promising solution for the next generation PONs", International Conference on Computer and Information Sciences, pp. 1-6, 2019.

[3] Houtsma, V., Chou, E., \& van Veen, D., "50 Gbps TDM-PON using Neural Network Enabled Receiver Equalization Specialized for PON",, Optical Fiber Communications Conference and Exhibition, pp. 1-3, 2019.

[4] Gill, H. K., Walia, G. K., \& Grewal, N. S, "Performance analysis of mode division multiplexing IS-OWC system using Manchester, DPSK and DQPSK modulation techniques", Optik, vol 177, pp. 93-101, 2019.

[5] Xia, J., Li, Z., Li, Y., Xu, T., Chen, J., Song, Y., \& Wang, M, "Comparison of NRZ and duo-binary format in adaptive equalization assisted 10G-optics based 25G-EPON", Optics Communications, vol. 410, pp. 328-332, 2018.

[6] Zhang, H. B., Wang, W. Q., Zheng, Z., \& Jiang, N, "Experimental demonstration of $25-\mathrm{Gb} / \mathrm{s}$ downstream transmission using $10-\mathrm{Gbps}$ optics for next-generation PONs", Optics Communications, vol. 427, pp. 209-214, 2018

[7] Spolitis, S., Kurbatska, I., \& Bobrovs, V, "Considering of PAM-4, DB, NRZ and RZ for Implementation in Next-Generation PONs", International Conference on Software, Telecommunications and Computer Networks, pp. 1-6, 2018.

[8] Dong-Nhat, N., Elsherif, M. A., Le Minh, H., \& Malek mohammadi, A., "NRZ versus RZ over absolute added correlative coding in optical metro-access networks", Optics Communications, vol. 387, pp. 30-36 2017.

[9] Paloi, F., Mirza, T., \& Haxha, S, "Optimisation of dispersion compensating in and long-haul fibre for RF transmission of up to 100 Gbit/s by using RZ and NRZ formats", Optik, vol. 131, pp. 640-654, 2017.

[10] Guo, Y., Yin, Y., Song, Y., Huang, M., Li, Y., Kuang, G., Li, M, "Demonstration of 25Gbit/s per channel NRZ transmission with $35 \mathrm{~dB}$ power budget using 25G Ge/Si APD for next generation 100G-PON", Optical Fiber Communications Conference and Exhibition, pp. 1-3, 2017.

[11] Kaur, A., Sheetal, A., \& Miglani, R., "Impact of optical modulation formats on $10 \mathrm{G} / 2.5 \mathrm{G}$ asymmetric XG-PON system", Optik, vol.149, pp. 351-358, 2017.

[12] S. Rajalakshmi., T. Shankar., "Optimization of Optical Amplifier Saturation power in NG-PON2 using 2048 way Splitter", Pakistan Journal of Biotechnology, Vol. 14 (Special Issue II) pp. 28-32, 2017.

[13] Kurbatska, I., Alsevska, A., Gegere, L., \& Bobrovs, V., "Comparison of modulation formats for use in the next generation passive optical networks", Progress in Electromagnetic Research Symposium, pp. 37833787, 2016.

[14] Choudhury, P. K., \& Khan, T. Z, "Symmetric $10 \mathrm{~Gb} / \mathrm{s}$ wavelength reused bidirectional RSOA based WDM-PON with DPSK modulated 
downstream and OFDM modulated upstream signals", Optics Communications, vol 372, pp.180-184, 2016.

[15] Agalliu, R., \& Lucki, M., "System improvements in dense wavelength division multiplexing networks by using advanced optical modulation formats", International Conference on Transparent Optical Networks, pp. 1-4, 2015.

[16] Wei, J., Cheng, Q., Penty, R. V., White, I. H., \& Cunningham, D. G, “ 400 Gigabit Ethernet using advanced modulation formats: performance, complexity, and power dissipation", IEEE Communications Magazine, vol 53(2), pp. 182-189, 2015.

[17] Xu, X., Zhou, E., Liu, G. N., Zuo, T., Zhong, Q., Zhang, L., \& Li, Z, "Advanced modulation formats for 400-Gbps short-reach optical interconnection”. Optics express, vol 23(1), pp. 492-500, 2015.

[18] S. Rajalakshmi, T. Shankar "Carrier Reuse using RSOA in TWDMPON for Broadcast and multicast Transmission", International Journal of Pharmacy and Technology, Vol 8, no 4, pp. 21470-21481, 2016.

[19] Yi, L., Li, Z., Bi, M., Wei, W., \& Hu, W., "Symmetric 40-Gb/s TWDMPON with 39-dB power budget", IEEE Photonics Technology Letters, vol. 25, no.7, 644-647, 2013.

[20] Ji, W, "40 Gbit/s per wavelength channel in WDM-RoF-PON with polarization multiplexing and CSRZ-QDPSK modulation", Optik, vol 125(1), pp. 366-369, 2014.
[21] Badhan, N, Sharma, N, "Comparative analysis of CSRZ, DB and DPSK modulation formats for single channel $40 \mathrm{~Gb} / \mathrm{s}$ system", International Conference on Medical Imaging, m-Health and Emerging Communication Systems, pp. 95-100, 2014.

[22] Curri, V., Carena, A., Poggiolini, P., Cigliutti, R., Forghieri, F., Fludger, C., \& Kupfer, T. (2014, March). Time-division hybrid modulation formats: Tx operation strategies and countermeasures to nonlinear propagation. In OFC 2014 (pp. 1-3). IEEE.

[23] Maneekut, R., Sakchaichanchon, T., Ket-Urai, V., \& Kaewplung, P., "Recent progress of the next generation 40-Gbps signal transmission over passive optical network using the advance modulation formats", International Conference on Optical Communications and Networks, pp. 1-4, 2012.

[24] Iwatsuki, K., "Application and technical issues of WDM-PON", Broadband Access Communication Technologies IV, Vol. 7620, p. 76200C. 2010.

[25] Winzer, P. J., \& Essiambre, R. J., "Advanced modulation formats for high-capacity optical transport networks", Journal of Lightwave Technology, vol. 24, no.12, pp 4711-4728, 2010. 